Revista Perspectivas Online: Exatas \& Engenharia Abril de 2019, v.09, n.24, p. 1 - 18 ISSN: 2236-885X (Online) DOI: $10.25242 / 885 X 92420191731$

\title{
ANÁLISE DE FALHA E DO PROJETO CONSTRUTIVO DE UM VASO DE PRESSÃO
}

\author{
Beatriz Covre Faria ${ }^{1}$, Bárbara Ferreira de Oliveira ${ }^{2}$, Silvio Eduardo Teixeira Pinto da \\ Silva ${ }^{2}$
}

\section{RESUMO}

FARIA, B. C.; OLIVEIRA, B. F.; SILVA, S.E.T.P. Análise de Falha e do Projeto construtivo de um vaso de pressão. Perspectivas Online: Exatas \& Engenharia, v. 09, n. 24, p. 1 - 18, 2019.

Neste artigo foi feita análise da falha e do projeto construtivo de um vaso de pressão geminado, que sofreu uma trinca transversal na região do anel de reforço e solda de interligação da parede horizontal do vaso com a vertical. Primeiramente foi feito ensaio não destrutivo por líquido penetrante para realçar a trinca e o ensaio por ultrassom para medição da espessura da parede do vaso. Para análise dos materiais, inicialmente foram retiradas amostras dos cilindros vertical e horizonal em regiões distantes do cordão de solda afetado a fim de realizar análise química e microestrutural da seção transversal do material de cada cilindro e determinação da dureza Vickers. As mesmas análises foram realizadas no entorno da trinca. A verificação do projeto utilizado foi realizada a partir do cálculo de espessura mínima admissível, pressão máxima de trabalho admissível (PMTA) e as dimensões mínimas necessárias para o anel de reforço ideal de acordo com as condições de operação estabelecidas pelo fabricante, empregado de acordo com o código de projeto ASME Seção VIII, Divisão 1. Também foi verificado se a montagem dos componentes na região danificada atendeu as tolerâncias estabelecidas estabelecidas pelo código. Após análise dos resultados, verificou-se que a falha foi ocasionada por um procedimento mal executado, que poderia ter sido evitado caso as recomendações do código tivessem sido acatadas.

Palavras-chave: Vaso de pressão; Falha; Projeto. 


\begin{abstract}
In this paper, the failure and constructive design of a germinated pressure vessel were analyzed, which experienced a transverse crack in the region of the reinforcing ring and weld. Initially a liquid penetrant inspection was done to reveal cracks and an ultrasonic test was conducted to measure the wall thickness of the vessel. Samples were initially taken from the vertical and horizontal cylinders of regions distant from the weld in order to perform chemical and microstructural analysis of the cross section of the material and determine Vickers hardness. The same analyzes were carried out in the welded region in order to verify if metallurgical changes caused by welding process were

analysis of the design used was based on the calculation of the minimum admissible thickness, the maximum allowable working pressure (MAWP) and the dimensions required for an ideal reinforcement ring according to the operating conditions established by the manufacturer, used according to the international design code ASME Section VIII, Division 1. It was also checked if the adjustment the welded section, where the crack was found exhibited a misalignment within the tolerances established by the code. It was verified that the failure was caused by a poorly executed procedure and it could have been avoided if the code recommendations had been performed.
\end{abstract} responsible for crack formation. The

Keywords: Pressure vessel; Failure; Design.

\footnotetext{
${ }^{1}$ Shimmer Inspection, Repair and Maintenance of Equipment LTDA - Rua Edilce Odiléia Martins, 95 - Parque Alphaville, Campos dos Goytacazes - RJ, 28024-440, Brasil

${ }^{2}$ Institutos Superiores de Ensino do CENSA - ISECENSA - Laboratório de Análise e Projeto de Sistemas Mecânicos LAPSIM - Rua Salvador Correa, 139, Centro, Campos dos Goytacazes, RJ, CEP: 28035-310, Brasil.

(*) e-mail: beatriz.covref@gmail.com

Data de recebimento: 07/05/2019. Aceito para publicação: 28/05/2019.
} 


\section{INTRODUÇÃO}

De forma geral, recipientes pressurizados, mesmo de pequenas dimensões, podem ser considerados vasos de pressão. Desta forma, tanto uma simples lata aerosol, como uma grande caldeira são considerados vasos de pressão (ASHBY, 2005). Durante seu projeto e etapas de fabricação, montagem e teste deve-se ter cuidados extremamente especiais por se tratar de um equipamento altamente importante para continuidade de um processo e porque uma falha pode ocasionar perdas materiais e humanas, além de litígios caros e prolongados.

Os vasos de pressão são considerados de alto risco devido ao somatório das variáveis quando refere-se à severidade das condições de trabalho e à possibilidade de armazenamento de fluidos nocivos e perigosos (LOSITO, 2015).

Existem duas principais causas para a falha de um vaso de pressão. A primeira é referente a um grande aumento da pressão interna devido à pressurização excessiva. Por estas razões, tensões acima da resistência à fadiga do material podem ser alcançadas causando ruptura do vaso. A segunda causa se dá devido à redução da resistência do material causada por corrosão, superaquecimento e defeito do material ou ainda algum impacto externo (MOSNIER et al., 2003).

Para minimizar a ocorrência de falhas em vasos de pressões, foi publicada no Brasil em 1978 a norma regulamentadora NR-13, que estabelece critérios severos quanto à inspeção e à operação de vasos de pressão. A NR-13 tem por objetivo a prevenção de danos às pessoas e às instalações. As medidas que tornam a NR-13 preventiva se dá a partir da realização de inspeções, instalação de dispositivos de segurança, identificações físicas, além de registros e documentos, projeto de instalação, manutenções e profissionais habilitados. O objetivo geral das normas de projeto é, basicamente, impor uma limitação para que as tensões nos componentes do vaso permaneçam dentro de valores admissíveis. A falha só é considerável quando há uma deformação excessiva devido à pressão exercida no vaso. Por exemplo, quando há efeito de falha por fadiga, somente considera-se falha após um rigoroso e detalhado estudo (HUPPES, 2009; CAMPOS, 2011).

No presente trabalho foi realizada análise de falha de um vaso de pressão que trincou durante o serviço em uma unidade petrolífera. O estudo teve como base dados do projeto, a composição química e a microestrutura do material, obsevações da fratura e ensaio de dureza.

\section{METODOLOGIA}

Neste trabalho foi investigada a falha em um vaso de pressão que era utilizado para a separação de ar e óleo de um compressor do tipo parafuso em uma indústria petrolífera. $\mathrm{O}$ ano de fabricação consta como 2009, sendo o código de projeto utilizado o ASME Seção VIII, Divisão 1 (1986). No ano de 2012 foi diagnosticada queda da pressão do sistema e pôde ser verificado que havia vazamento no vaso de pressão. Após o ocorrido o vaso foi diagnosticado com uma falha e substituído por outro semelhante. Como comumente esses tipos de equipamentos possuem extenso tempo de vida útil, houve a necessidade da investigação da falha. 
Foram relacionados dados estruturais e de projeto para que fosse feita uma análise das possíveis variáveis que ocasionaram a falha do vaso de pressão apresentado na Figura 1. Os dados respectivos ao equipamento, encontram-se na Tabela 1.

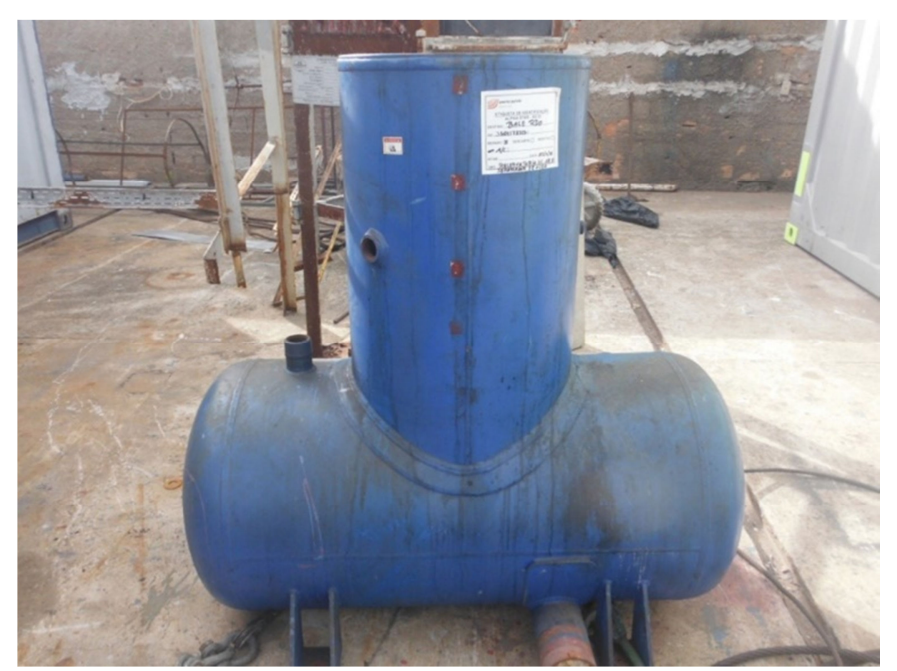

Figura 1: Vaso de pressão analisado

Tabela 1: Especificações do vaso de pressão analisado

\begin{tabular}{l|l}
\hline Código do Projeto & \multicolumn{1}{|c}{ ASME SEÇ̃̃O VIII DIV.1 (1986) } \\
\hline Material Casco e Tampos Elípticos & SA-414 Gr. C \\
\hline Material Tampo Plano Parafusado & SA-516 Gr. 70 \\
\hline Pressão máxima de trabalho admissível (MPa) & 1,2 \\
\hline Pressão de Teste Hidrostático (MPa) & 1,5685 \\
\hline Comprimento Vertical (mm) & 850 \\
\hline Comprimento Horizontal (mm) & 1300 \\
\hline Diâmetro Interno Casco Vertical (mm) & 503,76 \\
\hline Diâmetro Interno Tampo Vertical (mm) & 503,76 \\
\hline Diâmetro Interno Casco Horizontal (mm) & 604,83 \\
\hline Diâmetro Interno Tampo Horizontal (mm) & 606,77 \\
\hline Tensão de Ruptura (MPa) & 379,21 \\
\hline Tensão de Escoamento (MPa) & 227,53 \\
\hline Tensão Admissível SA-414 Gr. C (MPa) & 108,35 \\
\hline Tensão Admissível SA-516 Gr. 70 (MPa) & 137,895 \\
\hline Espessura Nominal Casco (mm) & 4,75 \\
\hline Espessura Nominal Tampo Elíptico (mm) & 3,78 \\
\hline Espessura Nominal Tampo Plano Parafusado (mm) & 38,10 \\
\hline
\end{tabular}




\subsection{Ensaio por líquido penetrante}

Embora a trinca esteja visível a olho nu, houve a necessidade da realização de um ensaio que pudesse realçar a extensão da trinca para que a mesma fosse medida. Adotou-se o ensaio não destrutivo por líquido penetrante (LP) que acusa descontinuidades superficiais.

\subsection{Medição de espessura por ultrassom}

Para realização da medição de espessura do vaso de pressão, foi feita a calibração do equipamento de acordo com um bloco padronizado pelo Instituição Nacional de Metrologia Qualidade e Tecnologia (INMETRO). A medição da espessura foi realizada à frio adotandose vaselina como acoplante entre a peça e o transdutor. Como este equipamento possui o recurso de medição sobre a película, não houve a necessidade de remover a tinta da superfície.

O sistema de identificação adotado foi numerar os pontos em ordem crescente, sendo que cada ponto foi medido em cotas diferentes, ou seja, cada ponto medido a $0^{\circ}, 90^{\circ}, 180^{\circ}$ e $270^{\circ}$, como pode ser visto na Figura 2.
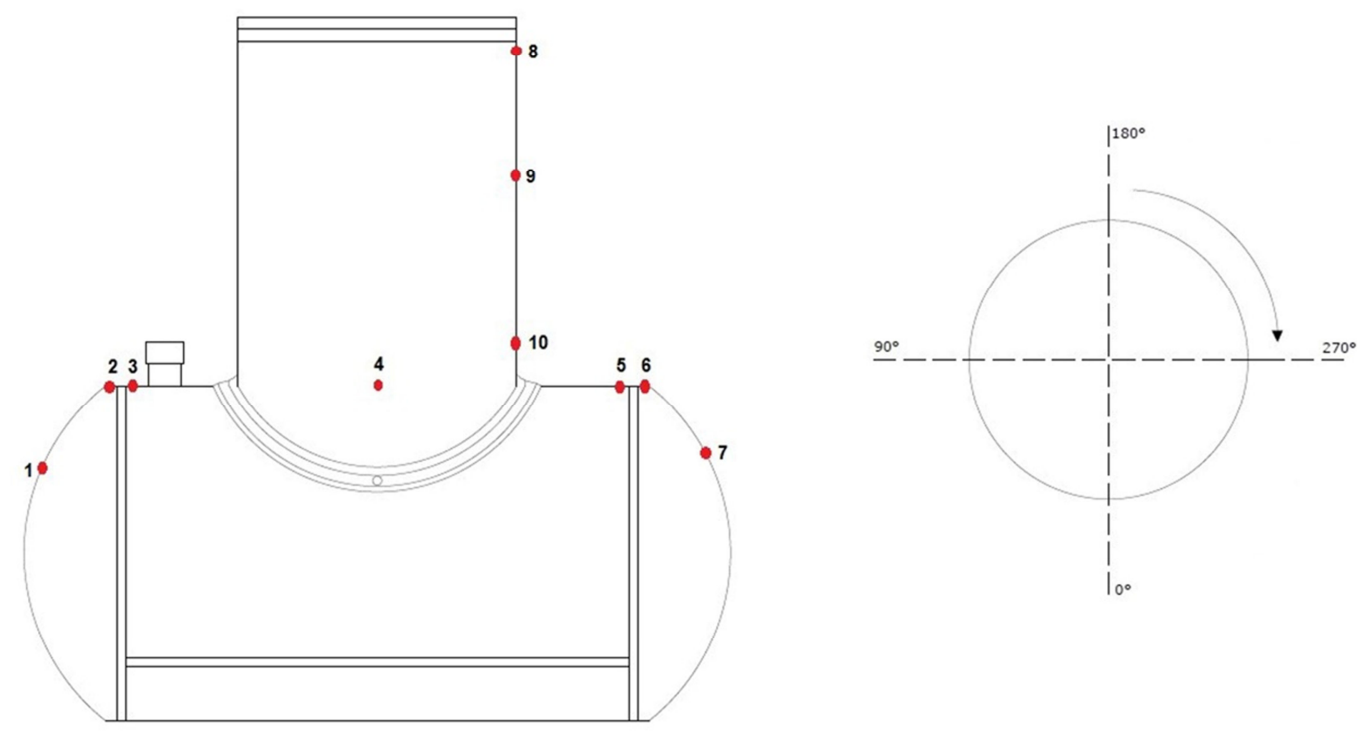

Figura 2: Desenho esquemático do vaso de pressão com os pontos de medição de espessura

\subsection{Amostragem}

A Figura 3 apresenta a demarcação do local de onde a amostra do vaso de pressão foi retirada. Primeiramente, uma amostra maior com $200 \mathrm{~mm}$ de extensão vertical e horizontal da região da trinca foi retirada com o auxílio de um maçarico. Em seguida, foi realizado um corte cauteloso desta amostra com uma serra manual para evitar uma análise errônea devido à alteração microestrutural ocasionada pelo calor. Este último corte foi realizado a aproximadamente $4 \mathrm{~mm}$ de distância da trinca no sentido vertical. 


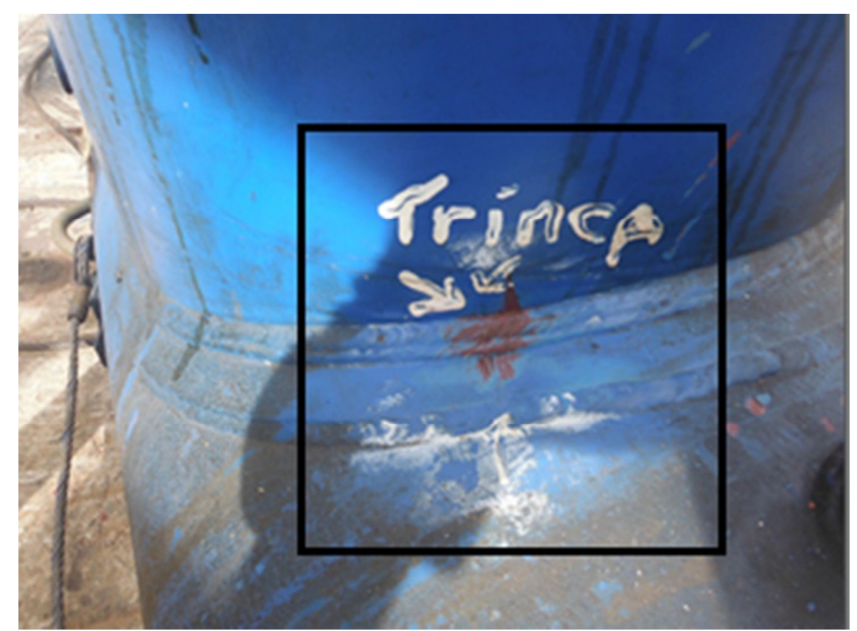

Figura 3: Região da Trinca

A partir dos cortes em uma serra fita foram obtidas 5 amostras: duas da região fraturada, uma amostra da parede vertical do vaso que continha a região de propagação da trinca, uma do metal base que não continha descontinuidades e uma da região trincada no anel de reforço.

\subsection{Análise química}

A análise química foi realizada por espectroscopia de emissão ótica por meio do espectrômetro SPECTROMAXX, conforme a norma ASTM E415 (2015). Foram verificadas as composições químicas por subdivisões de áreas especificadas na Figura 4.

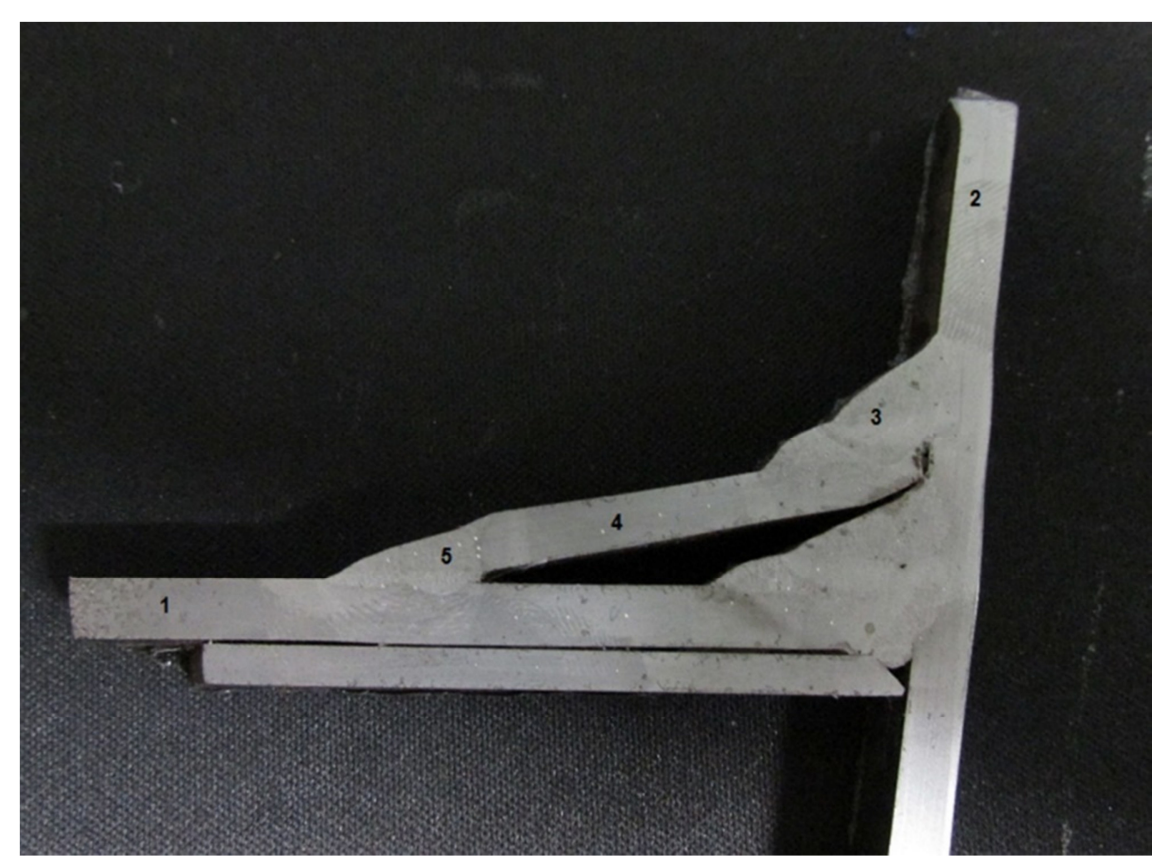

Figura 4: As áreas nas quais foram realizadas a análise química. 1: Metal Base da parede do vaso horizontal; 2: Metal Base da parede do vaso vertical; 3: Metal Solda da parede do vaso vertical com o anel de reforço; 4: Metal Base do anel de reforço; 5: Metal Solda do anel de reforço com a parede do vaso horizontal. 
O cálculo de carbono equivalente $\left(\mathrm{C}_{\mathrm{eq}}\right)$ foi realizado de acordo com a equação 1 (ASTM A6, 2001).

$$
C e q=\% C+\frac{\% M n}{6}+\frac{\% C r+\% M o+\% V}{5}+\frac{\% N i+\% C u}{15}
$$

\subsection{Análise da superfície da fratura}

A fim de possibilitar uma melhor análise da fratura do material foram obtidas macrofractografias por meio de um estereoscópio da marca OLYMPUS e modelo Infinity Lite no laboratório da Tecmetal.

\subsection{Caracterização microestrutural}

Amostras para caracterização microestrutural foram embutidas a quente com baquelite. Utilizou-se o procedimento de preparação metalográfica convencional por meio das etapas de lixamento, polimento e ataque químico em uma solução de Nital $2 \%$.

\subsection{Ensaio de dureza Vickers}

O ensaio de dureza Vickers foi realizado no durômetro TIME HVS-10 série 096 com uma carga de $10 \mathrm{kgf}$ seguindo a norma ASTM E92 (2017). As áreas nas quais foram realizadas as medidas de dureza estão demarcadas na Figura 05.

Conforme pode ser observado na Figura 05, o corpo de prova utilizado foi subdividido em 13 áreas, nas quais foram realizadas três medições de dureza Essas áreas foram divididas como segue abaixo:

- Metal Base da parede do vaso vertical (Pontos 1, 2 e 3);

- Zona Termicamente afetada da parede do vaso vertical com anel de reforço (Pontos $4,5$ e 6$)$

- Metal Solda da parede do vaso vertical com anel de reforço (Pontos 7, 8 e 9);

- Zona Termicamente afetada do anel de reforço (Pontos 10, 11 e 12);

- Metal Base do anel de reforço (Pontos 13, 14 e 15)

- Zona Termicamente afetada do anel de reforço com a parede do vaso horizontal (Pontos 16, 17 e 18);

- Metal Solda do anel de reforço com a parede do vaso horizontal (Pontos 19, 20 e 21);

- Zona Termicamente afetada da parede do vaso horizontal com anel de reforço (Pontos 22, 23 e 24);

- Zona Termicamente afetada da parede do vaso vertical com a parede do vaso horizontal (Pontos 25, 26 e 27);

- Metal Solda da parede do vaso vertical com a parede do vaso horizontal (Pontos 28, 29 e 30$)$;

- Zona Termicamente afetada da parede do vaso horizontal com a parede do vaso vertical (Pontos 31, 32 e 33);

- Metal Base da parede do vaso horizontal (Pontos 34, 35 e 36);

- Metal Base da chapa de reforço (Pontos 37, 38 e 39). 


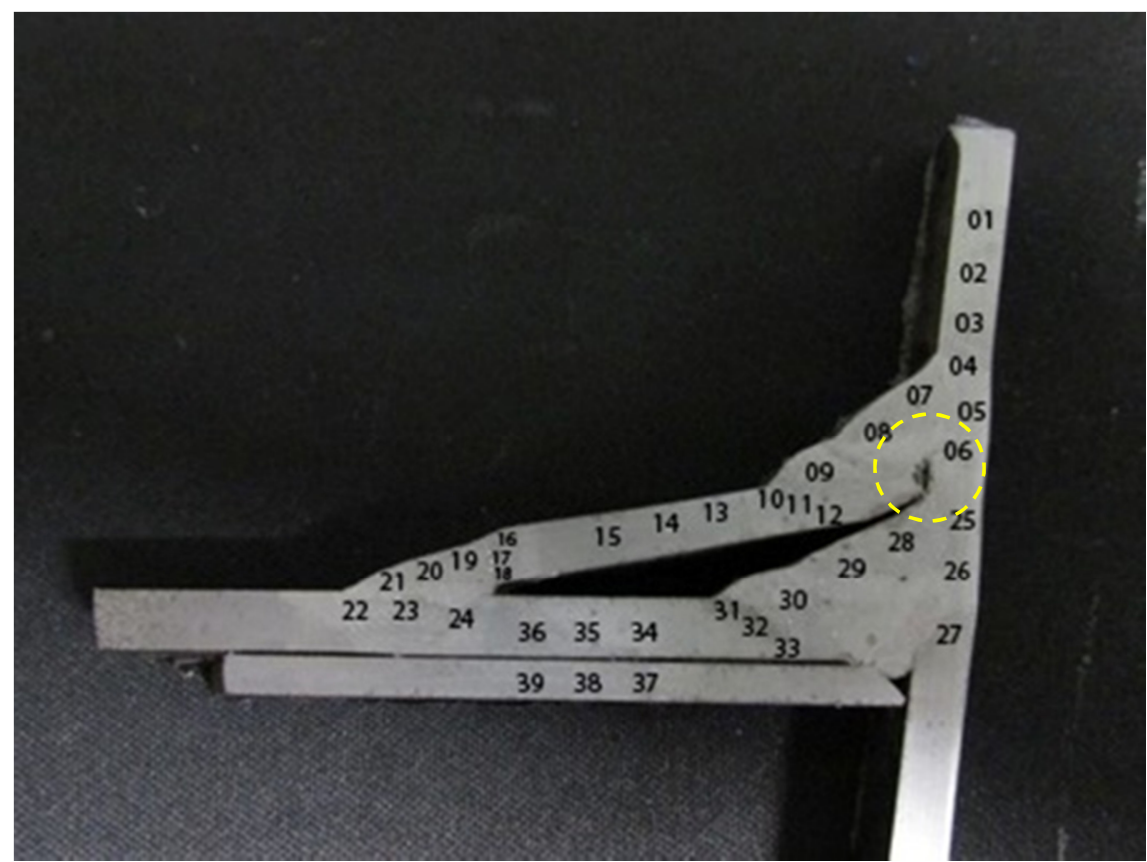

Figura 5: Corpo de prova utilizado no ensaio de dureza com as marcações enumeradas

\subsection{Análise estrutural do projeto}

Para fazer a análise estrutural do projeto foram adotadas 3 etapas. Primeiramente, foram analisadas as tensões normais dispostas nos vasos de acordo com a equação de equilíbrio em que afirma que a tensão circunferencial é o dobro da tensão longitudinal, ou seja, soldas e outros serviços no sentido longitudinal deverão ser evitados.

A segunda etapa consistiu em calcular as espessuras mínimas (e) e a pressão máxima de trabalho admissível (PMTA) para o casco cilíndrico, o tampo elíptico e os tampo plano parafusados de acordo com o ASME Seção VIII Divisão 1 (1986).

$\mathrm{Na}$ terceira etapa calculou-se a espessura ideal do anel de reforço de acordo com o código ASME Seção VIII Divisão 1 (1986). Foi utilizado o cálculo prático dos anéis de reforço em aberturas para fazer o comparativo com o vaso fabricado.

Por último, foi verificado se o ajuste da seção soldada na qual foi encontrada a trinca apresentava um desalinhamento dentro das tolerâncias estabelecidas pelo código ASME VIII Divisão 1 (1986).

\section{RESULTADOS E DISCUSSÃO}

\subsection{Ensaio por líquido penetrante}

A Figura 06 apresenta a descontinuidade após a realização do ensaio não destrutivo por LP. Foi encontrada uma trinca transversal à solda com $36 \mathrm{~mm}$ de comprimento. A princípio, essa trinca se estende da solda superior até o anel de reforço. 


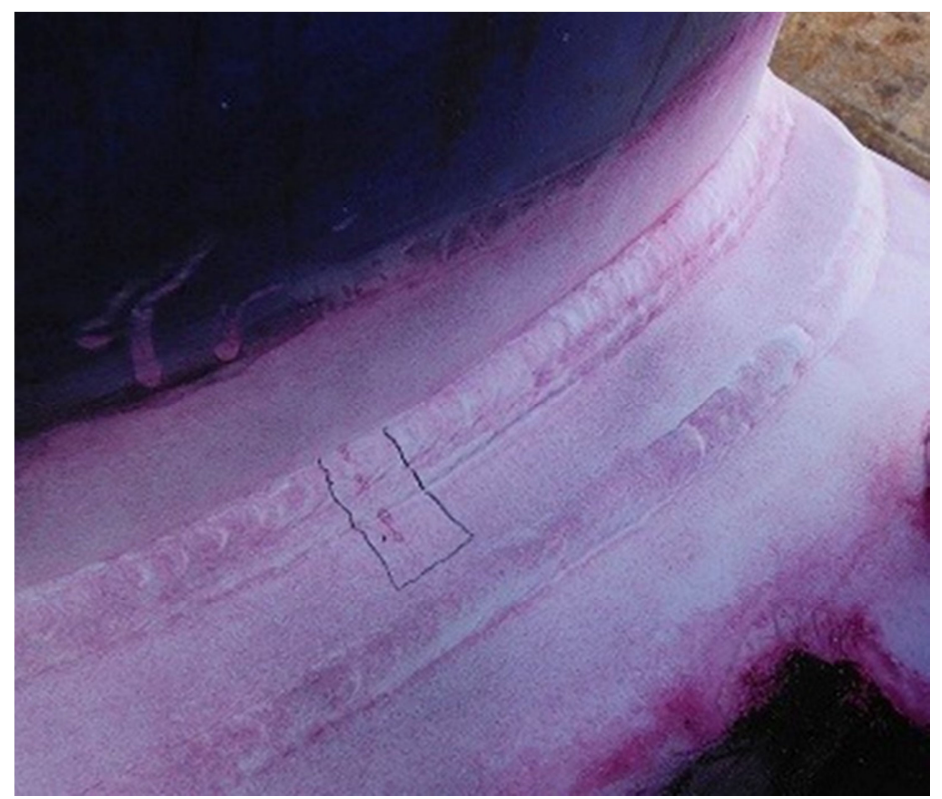

Figura 06: Descontinuidade demonstrada a partir do ensaio por líquido penetrante

O critério de aceitação utilizado para avaliar a descontiuidade encontrada foi o padronizado pelo código de projeto ASME VIII Divisão 1 (1986), que é a mesma norma utilizada para o projeto do vaso. Segundo o Apêndice 7, item 7.3, as indicações superficiais lineares determinadas por líquido penetrante são inaceitáveis se excederem $6 \mathrm{~mm}$ de comprimento. Já no Apêndice 8, verificou-se que as indicações superiores a 1,5 mm deverão ser relevantes, sendo que a indicação linear é a que apresenta um comprimento maior que três vezes a largura. Portanto, a trinca encontrada foi considerada relevante e tornou o vaso inoperante, não só pelo fato da mesma ser passante.

\subsection{Medição de espessura por ultrassom}

A Tabela 2 apresenta as espessuras reais encontradas pelo ensaio de ultrassom no vaso de pressão, de acordo com a esquematização apresentada na Figura 2. Para calcular a espessura mínima para resistir à pressão interna foram adotados os menores valores encontrados por áreas.

Tabela 2: Espessuras reais encontradas em cada ponto de medição

\begin{tabular}{c|c|c|c|c|c|c|c|c|c|c}
\hline \multirow{2}{*}{ Graus } & \multicolumn{10}{c}{ Pontos de Medição (mm) } \\
\cline { 2 - 12 } & 1 & 2 & 3 & 4 & 5 & 6 & 7 & 8 & 9 & 10 \\
\hline $0^{\circ}$ & 3,86 & 4,06 & 4,57 & 4,60 & 4,57 & 4,09 & 3,84 & 4,36 & 4,64 & 4,60 \\
\hline $90^{\circ}$ & 3,83 & 4,00 & 4,50 & 4,55 & 4,52 & 4,00 & 4,88 & 4,70 & 4,65 & 4,63 \\
\hline $180^{\circ}$ & 3,84 & 4,05 & 4,59 & 4,61 & 4,61 & 4,00 & 3,85 & 4,56 & 4,61 & 4,60 \\
\hline $270^{\circ}$ & 3,85 & 4,05 & 4,57 & ---- & 4,58 & 4,05 & 3,85 & 4,64 & 4,61 & 4,60 \\
\hline
\end{tabular}

Nos pontos 1, 2, 6 e 7, que equivalem ao tampo elíptico, o menor valor da espessura encontrado foi $3,83 \mathrm{~mm}$. Nos pontos 3 e 5, que equiavalem ao casco cilíndrico horizontal, o menor valor encontrado foi $4,50 \mathrm{~mm}$. Os pontos $4,8,9$ e 10 , que equivalem ao casco cilíndrico vertical o menor valor encontrado foi $4,36 \mathrm{~mm}$. 


\subsection{Análise química}

A análise química do material foi executada em 5 áreas diferentes, sendo estas apresentadas na Tabela 3 e Figura 4. Na mesma tabela também se encontram os valores do carbono equivalente determinados.

Tabela 3: Composição química do material encontrado em diferentes regiões

\begin{tabular}{c|c|c|c|c|c|c}
\hline $\begin{array}{c}\text { Elemento } \\
(\% \text { em } \\
\text { peso) }\end{array}$ & $\begin{array}{c}\text { Metal base } \\
\text { parede } \\
\text { horizontal }\end{array}$ & $\begin{array}{c}\text { Metal base } \\
\text { parede } \\
\text { vertical }\end{array}$ & $\begin{array}{c}\text { Metal solda } \\
\text { parede vertical - } \\
\text { anel de reforço }\end{array}$ & $\begin{array}{c}\text { Anel de } \\
\text { reforço }\end{array}$ & $\begin{array}{c}\text { Metal solda do } \\
\text { anel de reforço- } \\
\text { parede horizontal }\end{array}$ & SA-414 gr. c \\
\hline $\mathrm{C}$ & 0,226 & 0,167 & 0,147 & 0,254 & 0,191 & 0,25 \\
\hline $\mathrm{Si}$ & 0,0370 & 0,0036 & 0,690 & 0,0250 & 0,438 & -- \\
\hline $\mathrm{Mn}$ & 0,810 & 1,00 & 1,26 & 0,790 & 1,06 & 0,90 \\
\hline $\mathrm{P}$ & 0,0074 & 0,0052 & 0,0055 & 0,0070 & 0,0062 & 0,035 \\
\hline $\mathrm{S}$ & 0,0120 & 0,0150 & 0,0150 & 0,0120 & 0,0130 & 0,035 \\
\hline $\mathrm{Cr}$ & 0,0530 & 0,0220 & 0,0280 & 0,0480 & 0,0340 & -- \\
\hline $\mathrm{Ni}$ & 0,0520 & 0,0440 & 0,0440 & 0,0490 & 0,0460 & -- \\
\hline $\mathrm{Mo}$ & 0,0150 & $<0,002$ & 0,0063 & 0,0120 & 0,0083 & -- \\
\hline $\mathrm{Al}$ & 0,0740 & 0,0340 & 0,0210 & 0,0580 & 0,0310 & $0,02-0,08$ \\
\hline $\mathrm{Cu}$ & 0,112 & 0,0140 & 0,156 & 0,0930 & 0,131 & -- \\
\hline $\mathrm{Co}$ & 0,0160 & 0,0220 & 0,0110 & 0,0120 & 0,0130 & 0,20 \\
\hline $\mathrm{Nb}$ & 0,0030 & $<0,003$ & $<0,003$ & $<0,003$ & $<0,003$ & - \\
\hline $\mathrm{Sn}$ & 0,0100 & 0,0086 & 0,0085 & 0,0092 & 0,0082 & - \\
\hline $\mathrm{Carbono}$ & 0,3860 & 0,343 & 0,378 & 0,407 & 0,389 & - \\
\hline $\mathrm{Equivalente}$ & & & & & \\
\hline
\end{tabular}

Após a análise química, foi realizado um estudo comparativo com os dados padronizados do aço SA-414 Gr. C encontrados na norma ASTM A568 (2017) e ASTM A635 (2015). Dentre os elementos analisados da liga, pode-se observar que o elemento fósforo $\mathrm{P}$ e enxofre $\mathrm{S}$ estão abaixo do valor especificado na norma.

Foi verificado que o metal base atende a especificação da norma. De acordo com a norma ASTM A20 (2019), o carbono equivalente máximo estabelecido para espessuras de até $50 \mathrm{~mm}$ é igual a $0,45 \%$. Desta forma, pode-se observar que os valores encontrados obedecem a norma, o que garante uma boa soldabilidade, pois indicam que a tendência para a formação de martensita e de complicações é baixo (WEMAN, 2011).

\subsection{Análise da superfície de fratura}

Após os cortes e as análises, verificou-se que a região fraturada foi dividida entre duas regiões, que apresentavam diferentes espessuras possivelmente causadas por um desalinhamento durante a execução da solda. A Figura 7 apresenta as superfícies de fratura da região de maior (Figura 7a) e menor espessura (Figura 7b). Em ambos os casos observou-se superfícies relativamente planas, característica de fratura frágil. 


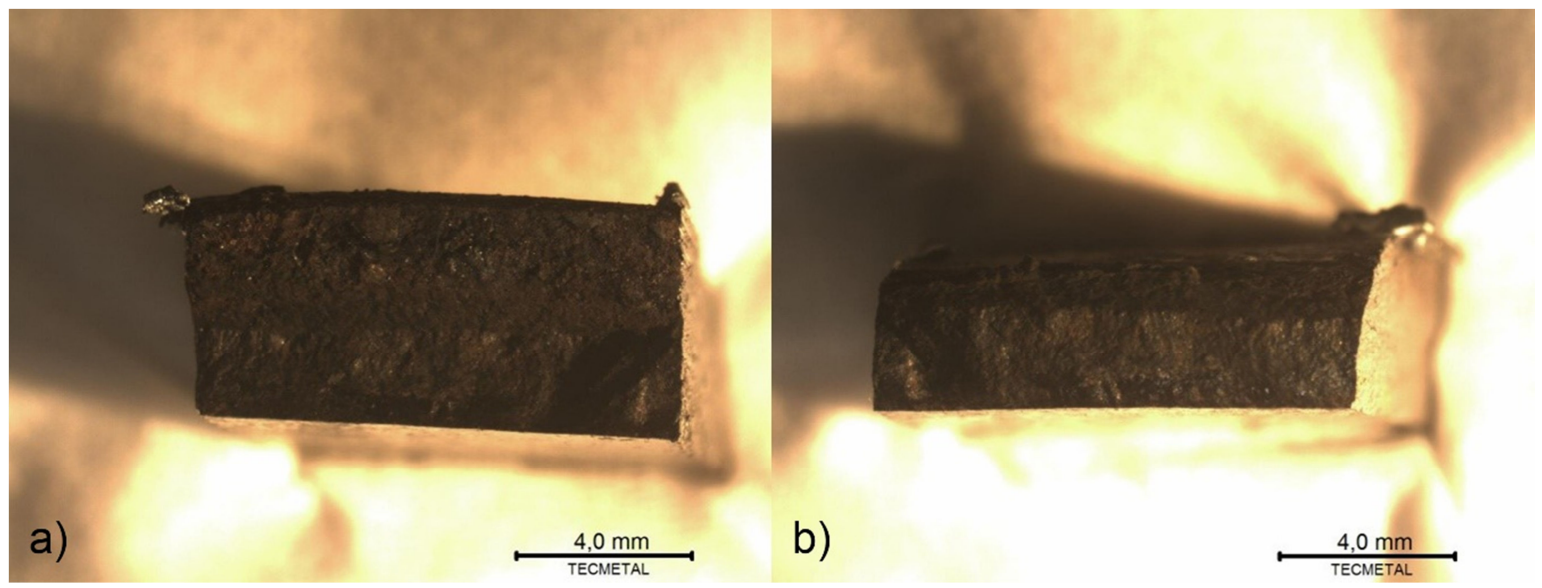

Figura 7: Superfície de fratura com característica de modo frágil nas duas regiões da fratura: a) região maior; b) região menor

\subsection{Caracterização microestrutural}

Nas Figuras 8 a e b são apresentadas as micrografias dos metais bases da parede horizontal e da parede vertical nos aumentos de 500x, respectivamente. Pode-se notar que a microestrutura do aço é constituída de perlita $(\mathrm{P})$ e de ferrita $(\mathrm{F})$, característica de aços com baixo teor de carbono.

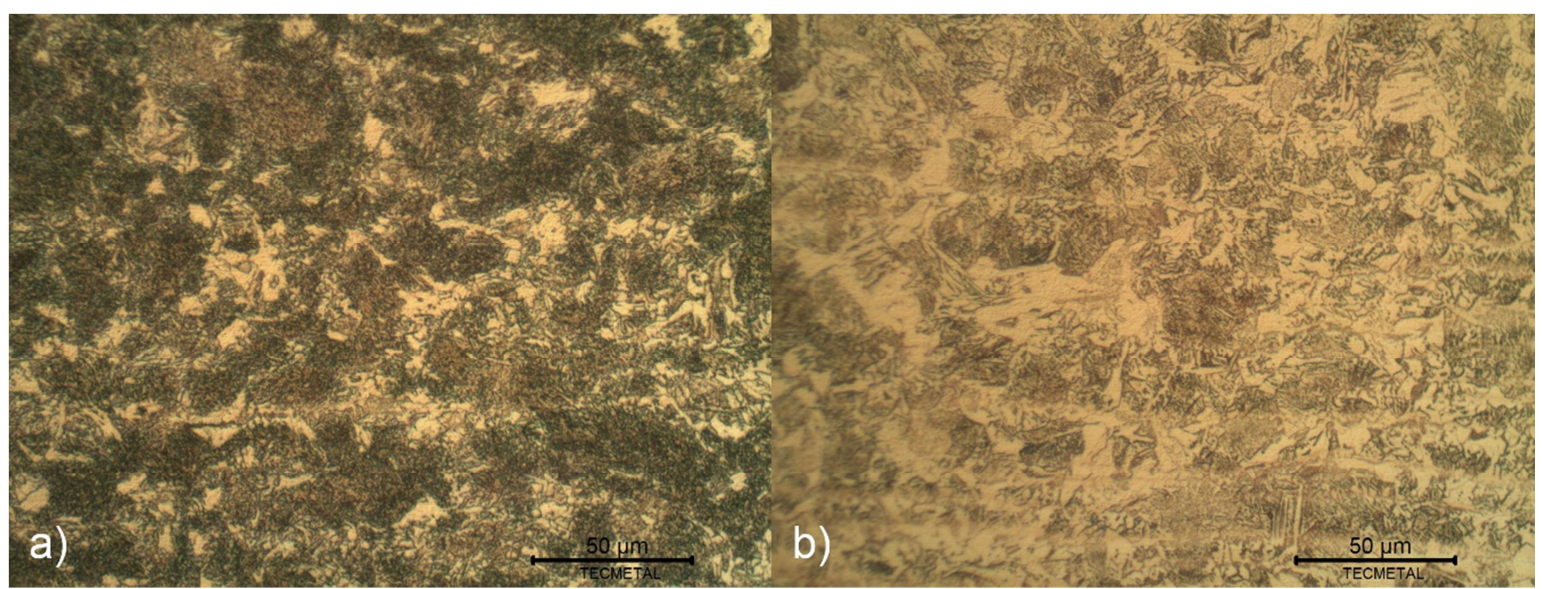

Figura 8: Micrografias dos metais base da parede a) horizontal e b) vertical

$\mathrm{Na}$ região da solda do anel de reforço com o vaso vertical foi verificada uma microestrutura constituída de uma matriz de ferrita acicular (FA), veios de ferrita alotromórfica (FAL) que nuclearam-se nos contornos dos grãos da austenita primária e placas laterais de ferrita de Widmänstten secundária (FWS), conforme mostrado na Figura 9. 


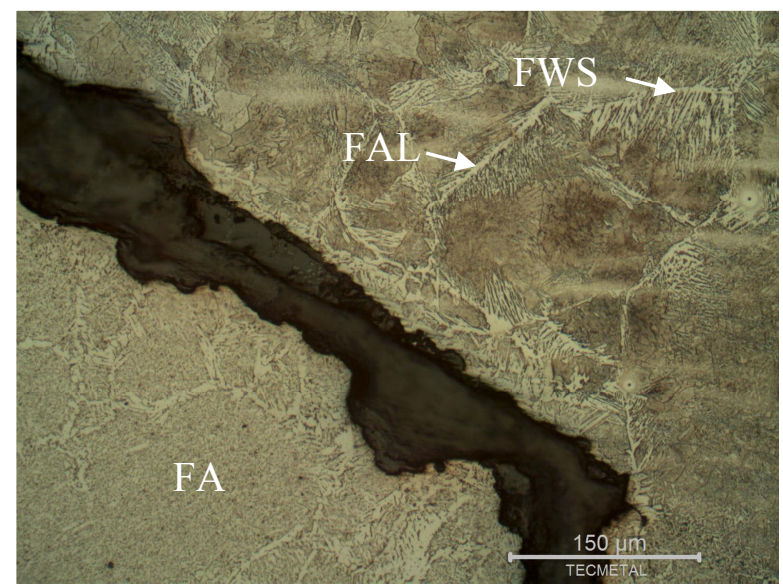

Figura 91: Micrografia da trinca no anel de reforço da parede vertical do vaso com aumento de 200x na interface entre a zona fundida e a zona termicamente afetada.

A presença de ferrita acicular foi reconhecida pela sua microestrutura "caótica", que é formada de placas lenticulares que crescem em muitas direções. Esta morfologia favorece a tenacidade à fratura, pois, de acordo com Mazancová, Rucká e Mazanec (2008), o arranjo intertravado e as interfaces de alto ângulo das placas atuam como obstáculos para a propagação de trincas de clivagem.

A presença de ferrita alotromórfica beneficia a formação da ferrita acicular, pois ocupa sítios propícios para a formação de outros microconstituintes concorrentes. No entanto, a ferrita alotromórfica também estimula a formação de ferrita de Widmanstätten que, segundo Babu e Bhadeshia (1990), é prejudicial à tenacidade, pois cresce num conjunto paralelo de placas com a mesma orientação, as quais oferecem pouca resistência à propagação de trincas.

Foi observado que nestas regiões a trinca propagou-se preferencialmente nas interfaces entre ferrita alotromórfica-ferrita acicular e ferrita de Widmanstätten-ferrita acicular. Isso pode ser explicado pelo fato da ferrita acicular apresentar uma dureza mais elevada que as ferritas alotromórfica e de Widmanstätten, favorecendo a concentração de tensão nestas interfaces.

Desta forma, com base análise microestrutural pode-se dizer que possivelmente a trinca foi nucleada na interface entre a zona fundida e a zona termicamente afetada na parede vertical do vaso e propagou-se através da zona fundida do material, onde a microestrutura apresenta constituintes mais frágeis. Apesar de a microestrutura apresentar maior resistência à propagação de trincas na parede vertical do vaso, a trinca se estendeu por ele causando o vazamento relatado.

\subsection{Ensaio de dureza Vickers}

$\mathrm{Na}$ Tabela 3 são apresentados os valores de dureza encontrados em diferentes áreas. De acordo com Grainger e Blunt (1998), as durezas HV da ferrita e da martensita encontramse em um intervalo de 150-250 HV e 500-1000 HV, respectivamente. Como pode ser observado no Tabela 3, os valores de dureza encontrados são satisfatórios, evidenciando que não houve a formação de fases duras e fragilizantes como a martensita, conforme foi verificado na análise microestrutural. 


\section{PERSPECTIVAS online}

De acordo com Miranda e Rodrigues (1994), a pressão do hidrogênio molecular pode causar a formação de trincas frágeis em aços baixo carbono. Como em altas temperaturas os metais no estado líquido tendem a dissolver o hidrogênio, a fragilização pelo hidrogênio pode se dar devido ao processo de soldagem, caso o hidrogênio fique retido no material após a solidificação. No entanto, a ocorrência de fragilização pelo hidrogênio não é influenciada somente pelo teor de hidrogênio. Os autores ainda afirmam que, para que haja ocorrência de trincas a frio induzidas, além da presença deste elemento, são necessários os seguintes requisitos: microestrutura favorável, tensão residual de tração e temperatura. Por exemplo, aços ferríticos são mais susceptíveis a este problema do que aqueles que apresentam matriz austenítica, pois o hidrogênio apresenta maior coeficiente de difusão na ferrita.

Desta forma, a partir do que foi exposto pode-se cogitar que o aço utilizado para a fabricação do vaso de pressão estudado poderia estar sujeito a este problema. No entanto, segundo Bruce e Etheridge (2012), adota-se como critério conservativo que abaixo de 350 HV10 não ocorre trinca a frio induzida por hidrogênio. Desta forma, exclui-se a fragilização pelo hidrogênio como causa da trinca encontrada no vaso de pressão, visto que todos as durezas se encontram abaixo do valor supracitado. Segundo Vitez, Budić e Sebastijanović (2000) e a norma NACE SP0472-15, em meios em que os aços carbono são mais suceptíveis à fragilização por corrosão sob tensão ou fragilização causada por sulfeto, é exigido que a dureza na zona termicamente afetada esteja abaixo de 250 HV10 e 248 HV10, respectivamente. Sendo assim, as durezas encontradas estariam apropriadas mesmo se o vaso estivesse sujeito a meios mais severos.

Tabela 3: Durezas HV10 encontradas em diferentes regiões do vaso

\begin{tabular}{l|c|c|c|c|c}
\hline Regiões & \multicolumn{2}{|c|}{ HV10 } & Média & \multicolumn{2}{c}{ Desvio } \\
Padrão
\end{tabular}




\subsection{Análise estrutural do projeto}

Considerando que a PMTA é igual a Pressão Máxima de Projeto (PMO), que equivale a 1,20658 MPa, verificou-se que as espessuras medidas por ultrassom encontram-se maiores que a espessura mínina calculada para todas as posições, conforme mostra a Tabela 4. Vale salientar que, para o cálculo das espessuras mínimas considerou-se que a margem de corrosão e a o coeficiente de eficiência de solda eram iguais a 0 (zero) e 0,85 , respectivamente.

Tabela 4: Espessura mínina calculada e espessura encontrada por ultrassom

\begin{tabular}{l|c|c}
\hline Posição & Espessura mínima calculada (mm) & Espessura medida por ultrassom (mm) \\
\hline Parede Horizontal & 3,99 & 4,50 \\
\hline Parede Vertical & 3,33 & 4,36 \\
\hline Tampo Elíptico & 3,02 & 3,83 \\
\hline Tampo Plano Parafusado & 27,07 & 37,51 \\
\hline
\end{tabular}

A Tabela 5 apresenta os valores de PMTA calculados para as menores espessuras encontradas através da medição de espessura por ultrassom. Foi verificado que as pressões máximas de trabalho admissível calculadas com as menores espessuras encontradas durante o ensaio de ultrassom são maiores do que a PMTA estabelecida no projeto. Desta forma, a atual condição do equipamento não ocasionou a falha.

Tabela 5: Pressões máximas de trabalho admissíveis calculadas

\begin{tabular}{l|c}
\hline Posição & PMTA (MPa) \\
\hline Parede Horizontal & 1,4 \\
\hline Parede Vertical & 1,6 \\
\hline Tampo Elíptico & 1,5 \\
\hline
\end{tabular}

Foi verificado que as pressões máximas de trabalho admissível calculadas com as menores espessuras encontradas durante o ensaio de ultrassom são maiores do que a PMTA estabelecida no projeto. Portanto, a atual condição do equipamento não ocasionou a falha.

Na Tabela 6 são apresentadas as especificações de espessura e largura necessárias para o anel de reforço do vaso de pressão. Inicialmente foi calculada a espessura mínima do anel de reforço para a maior largura possível. Em seguida, foi feito o cálculo do anel de reforço de duas formas. Na primeira, adotou-se que a espessura do anel era igual a espessura do casco do vaso e, na segunda, que era igual a espessura da chama do anel. Foi então observado que a largura adotada encontra-se dimensionada incorretamente. Em consequência disto, o anel de reforço não apresenta material suficiente para acomodar as tensões atuantes devido à retirada de massa no corte de abertura.

Foi observado durante a análise da fratura um desalinhamento da solda. O desalinhamento é um tipo de anomalia que sempre estará presente, mas é necessário separar o aceitável do inaceitável. O código ASME VIII Divisão 1 (2017) estabelece tolerâncias máximas de desalinhamento das arestas de soldagem de topo. Para juntas soldadas de todas categorias que apresentam espessura nominal da seção mais fina da junta de solda menor que 


\section{PERSPECTIVASConline CIENCIAS EXatas E ENGENHARIA}

13 mm, a ASME VIII Divisão (2017) determina que o deslocamento máximo entre uma face e outra deve ser igual a $1 / 4$ desta espessura. Foi determinado que o desalinhamento era de 1,14 mm. Para a espessura de $3,81 \mathrm{~mm}$, encontrada na região da solda, a tolerância do desalinhamento deveria ser igual a $0,94 \mathrm{~mm}$. Sendo assim, pode-se afirmar que havia um desalinhamento nesta região que ultrapassava o valor exigido pelo código supracitado tornando o vaso de pressão propenso à falha encontrada.

Tabela 6: Especificações necessárias para o anel de reforço

\begin{tabular}{l|c}
\hline Especificação & Medida calculada \\
\hline Espessura mínina do anel de reforço para maior largura possível $(\mathrm{mm})$ & 1,24 \\
\hline $\begin{array}{l}\text { Largura do anel de reforço considerando que a espessura é igual a espessura do casco do } \\
\text { vaso (mm) }\end{array}$ & 182,67 \\
\hline $\begin{array}{l}\text { Largura do anel de reforço necessária considerando que a espessura da chapa é a mesma do } \\
\text { anel (mm) }\end{array}$ & 228,27 \\
\hline
\end{tabular}

Este desalinhamento não foi verificado na parte externa, pois provavelmente esta região foi esmerilhada. A região interna permaneceu com um desalinhamento que deu origem a um concentrador de tensão. Como o vaso de pressão trabalha com ciclos de pressurização e despressurização, pode ser submetido à fadiga. Portanto, para evitar que problemas como este aconteçam, deve-se minimizar ao máximo a existência de concentradores de tensão a fim de aumentar a resistência à fadiga e, consequentemente, a vida útil do equipamento.

Também foi verificado, conforme pode ser observado nas Figuras 4 e 5, uma falta de fusão abaixo do cordão de solda do anel de reforço. Além disso, observou-se que o anel de reforço não está adequadamente posicionado, uma vez que existe um grande vazio entre o anel de reforço e a parede do vaso horizontal que, quando pressurizado, atua como um concentrador de tensões.

É importante mencionar que falhas como esta poderiam ter sido facilmente evitadas, mas Khattak, Makhtar e Kan (2016) revisaram as principais causas raízes de falhas em vasos de pressão verificando que o aspecto comum entre elas era a nucleação da trinca na zona fundida e na zona termicamente afetada pela solda. Este fato foi relacionado pelos autores com projeto insuficiente do reforço e mal execução do processo de soldagem, demonstrando que as falhas em vasos de pressão são causadas principalmente pela falta de cumprimento do código ASME VIII e de mão de obra especializada.

\section{CONCLUSÕES}

Neste trabalho investigou-se a causa da falha de um vaso de pressão separador de ar e óleo de um compressor proveniente da indústria petrolífera. Não foram verificadas alterações na composição química do material estudado que pudessem modificar as suas características tornando-o frágil e, consequentemente, propiciar a nucleação e propagação da trinca. Com base na análise microestrutural, pode-se dizer que a trinca foi nucleada na interface entre a zona fundida e a zona termicamente afetada na parede vertical do vaso e propagou-se através da zona fundida do material, onde a microestrutura apresenta constituintes com menor resistência à propagação de trinca. Apesar de a microestrutura apresentar maior resistência à 
propagação de trincas na parede vertical do vaso, a trinca se estendeu por ele causando sua falha. As pressões máximas de trabalho admissíveis encontram-se maiores do que a pressão máxima de operação estabelecida em projeto. Desta forma, pode-se afirmar que a falha não está associada à perda de espessura ou excesso de pressão atuante. $\mathrm{O}$ desalinhamento das arestas da soldagem de topo maior do que a tolerância aceitável pelo código de projeto do vaso ASME VIII, Divisão 1, em associação com a falta de uma solda longitudinal para união da placa do anel, e com o subdimensionamento do anel de reforço projetado, possivelmente provocou a falha. $\mathrm{O}$ anel de reforço utilizado não obteve dimensão suficiente para aliviar as tensões atuantes na área da abertura, que é um grande concentrador de tensões. Além disso, devido ao desalinhamento das chapas do anel de reforço e à falta de fusão da solda, criou-se outro concentrador de tensão, onde possivelmente a trinca foi nucleada, propagando-se para o vaso vertical e causando o vazamento relatado.

\section{AGRADECIMENTO}

Os autores agradecem a Shimmer Inspection, Repair and Maintenance of Equipment LTDA por ter cedido o vaso de pressão e a Tecmetal pela realização da análise química e dos ensaios mecânicos e metalográficos.

\section{REFERÊNCIAS}

ASHBY, M. F. Materials Selection in Mechanical Design. 3.ed. Oxford: ButterworthHeinemann, 2005. 624 p.

ASM HANDBOOK COMMITEE. Properties and Selection: Irons, Steels, and HighPerformance Alloys. American Society for Metals, v. 1, 1063 p., 1990.

AMERICAN SOCIETY FOR TESTING AND MATERIALS. ASTM A20-19. Standard Specification for General Requirements for Steel Plates for Pressure Vessels. Philadelphia, 2019.

AMERICAN SOCIETY FOR TESTING AND MATERIALS. ASTM A414-11. Standard Specification for Steel, Sheet, Carbon, for Pressure Vessels. Philadelphia, 2011.

AMERICAN SOCIETY FOR TESTING AND MATERIALS. ASTM A568-17. Standard Specification for Steel, Sheet, Carbon, Structural, and High-Strength, Low-alloy, Hot-rolled and Cold-rolled, General Requirement for. Philadelphia, 2017.

AMERICAN SOCIETY FOR TESTING AND MATERIALS. ASTM A635-15. Standard Specification for Steel, Sheet and Strip, Heavy-Thickness Coils, Hot-Rolled, Alloy, Carbon, Structural, High-Strength Low-Alloy, and High-Strength Low-Alloy with Improved Formability, General Requirements for. Philadelphia, 2015

AMERICAN SOCIETY FOR TESTING AND MATERIALS. ASTM E415-15. Standard Test Method for Analysis of Carbon and Low-Alloy Steel by Spark Atomic Emission Spectrometry. Philadelphia, 2015.

AMERICAN SOCIETY FOR TESTING AND MATERIALS. ASTM E92-17. Standard Test Methods for Vickers Hardness and Knoop Hardness of Metallic Materials. Philadelphia, 
2017.

AMERICAN SOCIETY OF MECHANICAL ENGINEERS. ASME Seção VIII - Divisão 1. Rules for Construction of Pressure Vessel Division 1. American Society of Mechanical Engineers. 1986.

AMERICAN SOCIETY OF MECHANICAL ENGINEERS. ASME Seção VIII - Divisão 1. Rules for Construction of Pressure Vessel Division 1. American Society of Mechanical Engineers. 2017.

BABU, S. S.; BHADESHIA, H. K. D. H. A direct Studdy of Grain Boundary Allotriomorthic Ferrite Crystallography. Materials Science and Engineering. v. 142. n. 2, p. 209-219, 1991.

BRUCE, W. A.; ETHERIDGE, B. C. Further development of heat-affected zone hardness limits for in-service welding. In: 2012 9th International Pipeline Conference. American Society of Mechanical Engineers, 2012. p. 71-81.

CAMPOS, M. A. Estudo das Instalações de Caldeira e Vasos de Pressão de uma Instituição Hospitalar sob Análise da NR 13. 2011. 80 p. Monografia (Curso de Especialização) - Universidade do Extremo Sul Catarinense, Criciúma, 2011.

GRAINGER, S. BLUNT, J. Engineering Coatings: Design and Application. 2.ed. Cambridge: Woodhead Publishing. 1998. 336 p.

HUPPES, R. M. Análise de Falha em um Vaso de Pressão. 2009. 17 p. Monografia (Bacharelado) - Universidade Federal do Rio Grande do Sul, Porto Alegre, 2009.

KHATTAK, M. A.; MUKHTAR, A.; KHAN, K. Azam. Common root causes of pressure vessel failures: a review. Advanced Research in Applied Mechanics, v. 21, n. 1, 2016.

LOSITO, R. M. Análise do Comportamento de um Vaso de Pressão em Condição de Teste Hidrostático. 2015. 58 p. Monografia (Bacharelado) - Centro Federal de Educação Tecnológica Celso Suckow da Fonseca, Rio de Janeiro, 2015.

MAZANCOVÁ, E.; RUCKÁ, Z.; MAZANEC, K. Contribution of Acicular Ferrite to the Increase Hydrogen Resistance Of Low Alloy Steel. Materiálové inženýrství. v. 2, p. 48-52, 2008.

MIRANDA, P. E. V.; RODRIGUES, J. A. Gases em metais e ligas: fundamentos e aplicações na engenharia. Rio de Janeiro, Editora Didática e Científica. 1994.

MOSNIER, D.; DAUDONNET, B.; RENARD, J.; MAYROTHALASSITIS, G.; MERCIER, Metallic pressure vessels failures. In: 25. ESReDA Seminar. European communities. Luxembourg, 2003. p. 129-141.

NATIONAL ASSOCIATION OF CORROSION ENGINEERS. NACE SP0472-15. Methods and Controls to Prevent In-Service Environmental Cracking of Carbon Steel Weldments in Corrosive Petroleum Refining Environments. Nace Internacional, 2010.

VITEZ, I.; BUDIĆ, I; SEBASTIJANOVIĆ, S; The control of cracks in pressure vessels 
exposed to aggressive media. Materiali in tehnologije, v. 34, n. 6, p. 433, 2000.

WEMAN, K. Welding Process Handbook. Woodhead Publishing, 2011. 280 p. 